\title{
My Views on Quality Teaching and Learning
}

\section{对优质教与学的看法}

\author{
Siu-tai Tsim 詹肇泰*
}

$\mathrm{T}$

EACHING and learning are twins! Quality teaching can be achieved in a very systematic process that involves development of outcomes-based syllabus, effective delivering of teaching activities, providing sufficient details and constructive guidance, timely feedback and comment as well as motivating, fair and transparent assessment tasks. Receiving pedagogy training could facilitate a faculty to be ready as a professional educator. Here, I would like to share some of my experiences in the actualization of students' development, some teaching tactics that I commonly used in the international summer programme, and how to keep myself motivated for continuous improvement.

教学相长! 高质量的教学可以在一个非常系统的过程中实 现, 该过程包括制定基于成果的教学大纲、有效地开展教学活 动、提供足够的细节和建设性指导、及时的反馈和评论以及激 励、公平和透明的评估任务。接受教育学培训可以帮助教师做好 作为专业教育者的准备。在这里, 我想分享我在学生发展的实践 中的一些经验, 一些我在国际暑期计划中常用的教学策略, 以及 如何保持自己不断进步的动力。

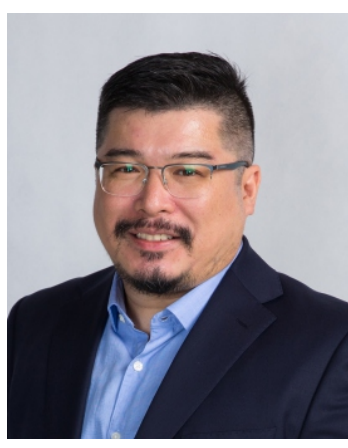

* Dr Siu-tai Tsim, Programme Director and Associate Professor of UIC's Environmental Science Programme.

詹肇泰博士, 北师港浸 大环境科学专业课程主 任、副教授。 


\section{Widening the exposure to society}

Since 2016, I have had the chance to develop and teach the Trinity-UIC Joint Summer Programme, I feel so thankful for this amazing and incredible experience. This summer course mainly studies the practices of Ecological Civilization from the past to present in China from science and cultural perspectives. I enjoy everything about this course including all the teaching activities, the involved American professors, the American students who participated and UIC students as well as the involved colleagues in the International Development Office, Whole Person Education Office and the Environmental Science Programme.

Before I joined UIC, I had worked in the field of Nature Conservation in Hong Kong SAR for more than 10 years, in this period of time I have gained solid experience in performing ecological study and survey, policy development, habitat management, environmental impact assessment, environmental publicity, and law enforcement etc. In addition, I have also accumulated some teaching experiences in Hong Kong Baptist University (HKBU) College of International Education and Open University Hong Kong Institute of Professional and Continuous Education. I believe all these relevant experiences help me to deliver my duties at UIC in the best way.

Reviewing the past nine years of services at UIC, there were four major experiences critically influencing my professional development in higher education: the first is Poster Presentation Event of the Division of Science and Technology (DST), the second is Faculty Professional Development Scheme, the third is TrinityUIC Summer Programme, and the forth is being a visiting scholar in Trinity University. Without coming across the first two experiences, I don't think I could make the Trinity-UIC Summer Programme as good as the present.

\section{Students all want to be valued and recognised}

The first important experience happened in 2012 and 2013. I had an idea of organising an academic symposium for the undergraduates in DST, so I made a proposal to the then Dean Professor Stephen Chung. The Dean enjoyed this idea, but he asked me to give a presentation to persuade other programmes in the Division Retreatment Meeting. Finally, the idea was supported. In March 2013, we had made the first Undergraduate Science and Technology Poster Presentation Event, and produced an abstract book for all the poster presenters. If you look at the faces of the poster presenters in the venue, you could find that their eyes were shining and they were speaking in great excitement of their research. All of them tried their best to introduce their research results but the venue immediately became loud and everybody was heated in the atmosphere. 
The presenters felt proud of their research projects, this was the most beautiful scene and moment that I will always keep in my mind. All the students want to be valued, especially because they have spent time and effort on their projects. Unfortunately, not all undergraduates had a chance to give presentations in an academic conference. This does not mean that they are not good enough, this means that we need to build a platform to motivate students to work harder in research. After that, the poster presentations have become a major reputable annual academic event of science students and DST.

\section{Establish an appropriate level of competition and peer pressure among students}

The DST Poster Presentation Event shows us that students demand a platform to demonstrate themselves. In my opinion, the ideal platform is one that creates an appropriate level of peer pressure and competition among students, which can make students feel the need to work harder; otherwise, they would not have desirable return. This relates to our society and the way it operates in a similar manner. On this platform, teachers' and peers' feedback becomes the best encouragement. In addition, this environment gives the best motivation to students to do better the next time because they feel respected and recognised.
This platform could be applied in different levels ranging from a course to collegewide; we could create many platform models in UIC. The "Innovative Food Carnival" of FST, "Earth Week" of Whole Person Education (WPE) Environmental Awareness, and "Final Show and Exhibition" of WPE Experiential Arts are the examples of course-level platform. The "24 Frames Graduation Exhibition" of Cinema and Television (CTV) and "Culture, Creativity and Management (CCM) Annual Exhibition" are the examples of programme-level platform.

The "Undergraduate Science and Technology Poster Presentation" is the model of Division-level platform. Whether we could unlock the positive feedback loop in education or not, it critically depends on the faculty's vision, attitude and commitment in teaching. In contrast, it might be a disaster to students' learning in a liberal arts college if the faculty does not have passion in modernising his/her teaching skills and applying creative teaching to his/her class.

\section{Give a very different learning experience to your students}

The second important experience that is greatly influencing me is the "Faculty Professional Development Scheme" (FPDS). As I know, the aim of FPDS is to develop the faculty's skills in performing high-quality teaching. They want to implement Outcomes-based Teaching and Learning (OBTL), enhance student 
engagement and teaching interactions, develop appropriate Criterion-Referenced Assessment (CRA) and teach critical thinking, innovation and creativity etc. The FPDS consists of four parts: the first part was a series of workshops offered by the Centre for Holistic Teaching and Learning of Hong Kong Baptist University (HKBU) in 2012, the second part was a one-week intensive workshop offered by the Joint Faculty Institute of Minnesota Private College Council (MPCC) and UIC in July 2013 at St. Catherine University (Minnesota, US), the third part was another series of workshops offered by HKBU, and the final part was the follow-up workshops offered by MPCC and UIC in July 2014 at UIC in Zhuhai (China).

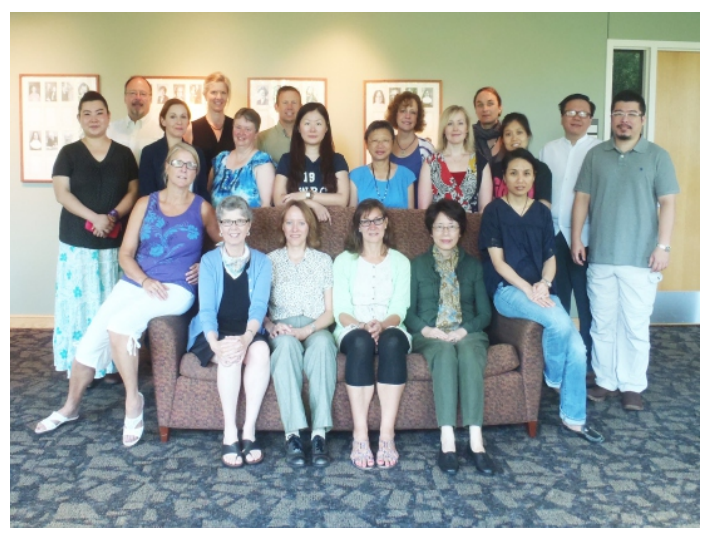

Group photo of the participants and trainers from MPCC and UIC in Faculty Development Institute (2013)

I feel so thankful and appreciate the chance to be one of the eight teaching staff members to participate in FPDS. When I was an undergraduate student in the 80'90 's, lecturing was almost the only kind of teaching activity given by the professors at that time. After my undergraduate, I was trained as a researcher in biology and nature conservationist in my postgraduate, post-doctoral and on-work training. In other words, I basically did not receive systematic educational training; in this connection, I believe many faculties may have a similar experience with me. However, to many students who are don't intrinsically behave as active learners, lecturing may kill their learning motivation!

Through FPDS, I could gain more ideas about quality teaching from experienced professors who are teaching at the renowned liberal arts colleges in the United States. I have widened my horizon in education and pedagogy during our idea exchange and case sharing. After the training, I have integrated some more kinds of teaching activity in my courses; from my experience, I can feel how the appropriate application of pedagogy can positively influence the effectiveness of teaching and learning.

\section{OBTL and CRA can help students more easily succeed in learning}

Some students know a few things about personal growth and career development in the society; in other words, only a few of them have thought about the questions such as, why they need to learn, how to learn, what they want to be and where they want to live etc. Similarly, students may not be able to visualise the importance of a 
course that benefits their future and career development. If students are confused on the value of a single assessment task, a course syllabus and contents, or even the curriculum design, they have a higher chance of getting lost in class and may have trouble learning, in the worst situation the student might lose interest in studying all subjects. Therefore, my general practice is to let students be told the value of learning outcomes and assessment tasks. From my opinion, if the assignment or project was more closely connected to society and real scenarios, it would be more successful to arouse students' study interests and motivation.

Giving a clear assignment guideline that shows all the details of requirements and assessment criteria can help my students succeed in learning. We could set targets at different difficulty levels in order to always give some true challenges to talented and/or hardworking students. In addition, giving bonus points in the assessment can be an attraction to help students reach higher achievement. In my experience, many students try a more challenging task; no matter if the student can successfully achieve the higher task or not, those who are more willing to try a task they might not achieve will gain experience and skill enhancement. I have received focus training on Outcomesbased Teaching \& Learning (OBTL) when UIC was requested to adopt OBTL and Criterion-Referenced Assessment (CRA) in $2013 / 14$, I was chosen to pilot the CRA in my courses and coordinate the implementation of CRA in DST.

\section{Students perform better when they receive teachers' timely constructive feedback}

It would be difficult for students to learn effectively and improve significantly if they only receive information about their grades from professors. One of the significant advantages of studying in a liberal arts college is the relatively small average class size, and under this circumstance, students can receive more support and guidance from professors, therefore students could develop faster and with more comprehension. In the class, I would encourage more teacher-student and student-student interactions; students could enhance their critical thinking by learning how to ask basic questions, repeating the practice of logical reasoning, and criticising other people ideas. After the class, I would meet my students to hear their progress in preparing the project and provide immediate steering advices by questioning students. Furthermore, I would give written feedback to students' assignment, so that they will know which part is good or bad, and also how to perform better the next time.

\section{Prepare well and present the best performance all the time}

"Like father like son" can be applied to educators, so I always remind myself and 
my colleagues to prepare well and perform with excellence, because students might treat us as their role model, and because opportunities always arise for those who are well prepared. Without the first and second important experiences, I may not have had the opportunity to develop Trinity-UIC Summer Programme - the third important experience to me. Five years ago, I gave an oral presentation in the "International Forum on Ecological Civilization and Higher Education" held at UIC on 26 May 2014. All the eight speakers of this Forum were either from UIC or the Associated Colleges of the South (US). Those visitors were of very high ranking as they were representing the renowned liberal arts colleges in the South of United States. As usual, I had studied the theme of the forum intensely and asked myself to present my best to the fellow visitors. I noticed that my presentation had drawn the attention of Prof Stephen Field's, a professor of Trinity University. One year later, in the summer of 2015, Prof Field and Prof David Ribble visited UIC and initiated the collaboration of summer programme with the UIC Environmental Science Programme. After one year of communication and preparation, we have finally delivered the first Trinity-UIC Joint Summer Programme at UIC in June 2016.

The theme of this summer programme is to explore how China practices "Ecological Civilization" in the past and present from a nature conservation perspective. The Programme consists of three main learning contents: (1) learning Chinese language,
(2) experiencing Chinese culture and heritage, and (3) studying a three-week credit-bearing course named "The Ecology and Bio-conservation in China". I am mainly responsible for the development, coordination, and delivering of this creditbearing course at UIC. The course is cotaught by professors from the US and China and also has students from the US and China, because of this we have developed the syllabus and we have considered and managed the students' needs and expectations from the views of students from West and East. We have integrated nine key elements in developing the syllabus, in order to make the course meaningful and more attractive; and for the learning outcomes to be achieved (Table 1). When I look back, this co-teaching experience helps me to further develop my enthusiasm and skills in teaching.

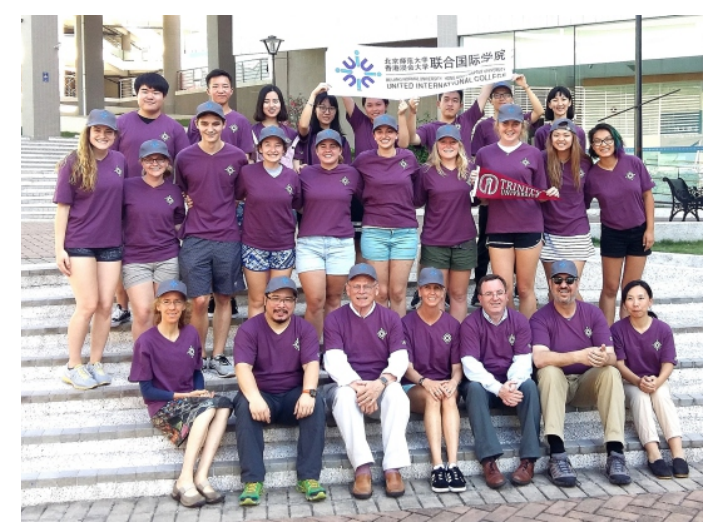

Group photo of Trinity-UIC Joint Summer Programme 2017 
(Table 1) The nine key elements in developing the syllabus of "The Ecology and Bioconservation in China"

\section{Professors co-teaching}

\section{from the US and China}

Co-teaching means that each professor who is involved will teach their expertise and most familiar topics in order for students to learn the best from each professor. Students could be inspired by hearing different views or questions raised by the professors from other universities. We have adopted an in-depth mode of co-teaching that means two or more professors were attending the class together. When one professor was teaching, the other professors were observing, if necessary, the observing professor might ask questions or support the students' discussion. Hence, not just the students can benefit from coteaching, but also the professors can benefit by high-quality interacting with other professors who have different academic and cultural backgrounds. From 2016 to 2019, I had the opportunity to learn other teaching styles and practices when co-teaching this course with four American professors from Trinity University and Southwestern University - Prof David Ribble, Prof Jonathan King, Dr Kelly Lyons and Dr Carl Robertson. We believe such arrangement could maximise the vision of students.

\section{Peer learning with students from the US and China}

We have adopted two kinds of peerlearning modes in this summer course. The first kind of peer-learning is to let Chinese students learn from American students, or vice versa. For example, we have asked UIC students and American students to present the biodiversity and natural environment of China and US respectively, so even though our UIC students were studying in Zhuhai, they could know something new about US. Similarly, American students could learn more about China's environment from UIC students.

The second kind of peer-learning is an in-depth mode of cross-cultural and academic background learning. For example, we have arranged two UIC and two American students to form a study group of four throughout the first half of the summer programme. Moreover, we tried to balance the male to female ratio and average academic performance in grouping. After completion of the first half, we reformed the student grouping using the same principles. We believe such arrangement could maximize the effectiveness and outcomes in peer-learning. 


\section{Course-based}

\section{Undergraduate Research Experience}

C.U.R.E. (Course-based

Undergraduate Research Experience)

has been proven to give positive learning outcomes on the development of students' conceptions and practice of scientific thinking, because of this we have tried to adopt C.U.R.E. in this summer programme. Students were getting involved in some long-term research projects such as the seagrass community study and campus amphibian survey, so that they could learn the principles of developing scientific research and data analysis. From the professor's view, those students were valuable manpower in assisting with the collection of data. More importantly, students' curiosity in learning could be satisfied in C.U.R.E.

\section{Exploring and experiential learning experience}

Observation is the first step in performing scientific research, so we have designed some assignments to motivate students to explore and discover by themselves. A man who travels far knows more! Our purpose is to develop students' observation and consolidation of information during traveling. Furthermore, we have tried to synergise the teaching outcomes by integrating learning activity into traveling. For example, since students would have many chances to travel and have a meal in downtown Zhuhai, we have asked them to identify the green city design(s) of Zhuhai (China) and San Antonio (US). Students need to explore the city by themselves, and then make comparisons of these two cities.

For another example of experiential learning we have arranged a food cooking lesson for students, each group was assigned to cook two dishes in Chinese style using local wetland plants. During cooking, students can learn the morphological characteristics and ecological adaptations of wetland plants as well as the impacts of diet culture to nature. To American students, they could also learn how to cook Chinese dishes. We believe such arrangements could impress students and leave a longer memory.

\section{Using the uniqueness and specificity of surrounding environment in teaching}

Why do we travel? One of the reasons is so we could see something unique and special during travel, and those 
things that could not be found in your home country. The same question, why do American students come to UIC and study during this summer programme in Zhuhai? Therefore, we have used some unique and specific habitats of Zhuhai as study objects. For example, those unique places in China are Fengshui woodlands, Fengshui village layout, Fengshui architecture, lychee orchard in Huitong Village, rice paddy field, intertidal area, and conventional seafood market, bird market and aquarium fish market etc.

\section{Interdisciplinary study - the impacts of heritage and cultural on nature, or vice versa}

In order to study the interactions of cultural heritage, international trading and biodiversity extinction, we have used dolphin and croaker extinction as the case study. To obtain the whole picture of this global issue, in addition to attending lectures, students have visited many places including dolphin watching at Tung Chung in Hong Kong, they visited the dried seafood market at Tai $\mathrm{O}$ in Hong Kong, visited the Chinese White Dolphin National Nature Reserve Management Office and the Dolphin Rescue Facilities on Qi'ao Island in Zhuhai, so that they have learned the habitat and threats of dolphin as well as international dolphin conservation programme.

\section{Demonstrate the power of team working and sharing}

Students were assigned to perform several large scale ecological surveys in groups. The survey data collected by the whole class was pooled together for use in students' final presentation. In the beginning, the groups had no idea which topic will be their final presentation topic; however, all groups have been told to try their best to complete the data collection and their performance in data collection has been graded. Under this circumstance, the power of team working and sharing would be demonstrated and highlighted.

\section{Apply a variety of teaching activities}

In order to engage students' learning and facilitate students' understanding, we have applied many kinds of teaching activities in this summer programme. For example, pre-reading materials, using e-Learning and mobile devices, video learning, group discussions, concept maps, lecturing, field visits, field study and surveys, oral 
presentations, news sharing and group

discussions etc.

\section{Other tips to engage} students' learning:

- Let students feel you have paid attention to each of them. For example, knowing all the students' names, being able to speak out their names in the class, and ask them questions.

- The conventional classroom setup is limiting teacher-student and student-student interactions. In this summer programme, we have re-arranged the classroom desks in an island form - l'd like to call this is an "interactive classroom setup", students were sitting at the sides of island desk, so the professor could more easily reach every student without difficulty.

- Teach the subject or topic that you love and feel proud.
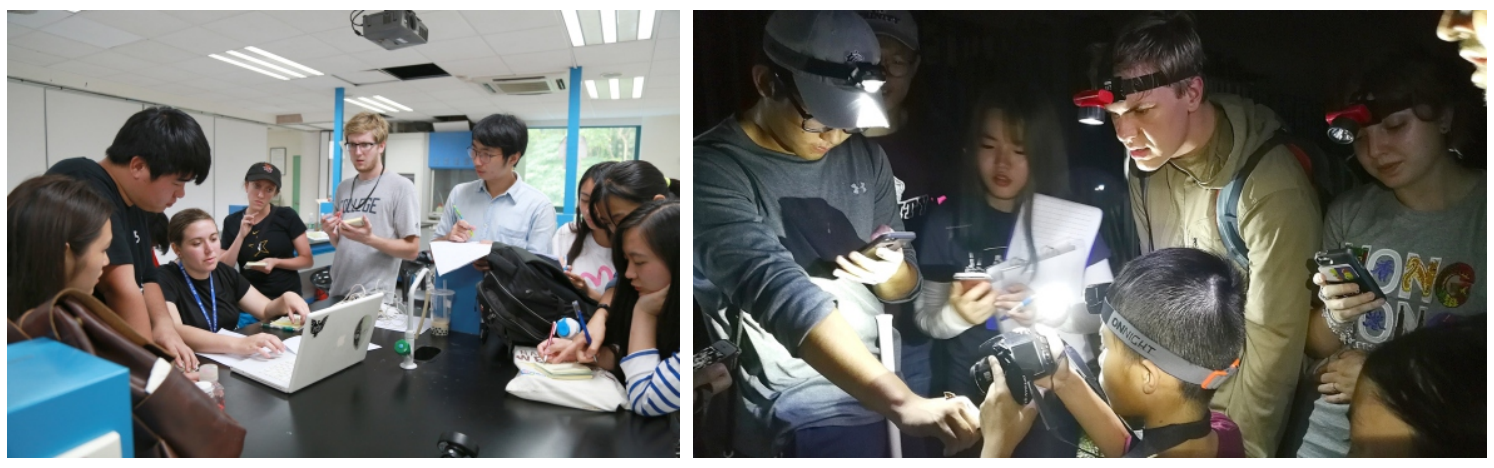

Co-teaching and learning of the Trinity-UIC Ecology and Bio-conservation Programme in action

Reading the comments of students who have completed this summer programme in different years, I believe that we have done the right thing.

\section{Students' comments in different years}

- "This course is excellent! A lot of case studies and field trips helped me to apply what we learned into real case analysis. In-class discussions required everyone to contribute to make a conservation plan, a concept map or something. It helped me to learn how to work as a group and how to back up my group members." (2016)

- "The lectures of this subject have 
been very thorough and all instructors are extremely knowledgeable about their studies." (2017)

- "Fieldtrips were clearly and thoughtfully applied to what we learned in class." (2018)

- "I learned how to implement the scientific method, about critical questions, realized I need to make my role in presentations more substantive. Learned to open my eyes to my surrounding environment. I am much more aware now." (2019)

- "The study of Chinese culture and the study of ecology were both masterfully blended together, reflecting the idea of ecological civilization." (2019)

\section{The challenge and the opportunity of being a visiting scholar}

In Semester 1 of 2018/19, I was invited to be the Visiting Scholar of Biology Department in Trinity University (Texas, US) - this is the fourth important experience to me. The last time that I stayed at an American university was when I was a Postdoctoral Research Fellow, basically I just focused on research work. However, the experience of being a visiting professor was so different because I was completely immersed in a western higher education system. I needed to teach a senior course, give a seminar, and attend academic conferences in the six months of sabbatical leave period. At Trinity University, a renowned liberal arts college, I observed that students are very motivated, their questions raised in the class are so challenging and critical because they come well prepared to every class and well trained to be a thinker. Professor to student ratio is about 1:20 there, so professors could have sufficient time to pay attention to every single student's development. From the student's angle, they are very concentrated on the professor's presentation and learning activities. I don't believe I could survive and be an appropriate visiting professor at Trinity University if I did not have the first three important experiences in UIC. Although I was facing some challenges as a visiting professor at Trinity University, it is indeed a perfect environment to further develop my profession in education. I appreciate that I have had this excellent opportunity in my career development. $\mathbb{E}$ 